\title{
Influence of Temperature on the Global Spread of COVID-19
}

\author{
Indrani Roy ${ }^{1}$ \\ ${ }^{1}$ Affiliation not available
}

November 26, 2020

\begin{abstract}
.
Hosted file

Influence of Temperature on the Global spread of COVID-19 and Solutions.pdf available at https://authorea.com/users/336178/articles/461953-influence-of-temperature-on-theglobal-spread-of-covid-19
\end{abstract}

\section{Influence of Temperature on the Global Spread of COVID-19 and Solutions}

Indrani Roy

University College London (UCL), IRDR, indrani.roy@ucl.ac.uk

\begin{abstract}
.
This article investigated whether the atmospheric temperature had any role in the spread and vulnerability to COVID-19 worldwide and how that knowledge can be utilized to contain the fast-spreading disease. It highlighted that temperature was an important factor in transmitting the virus, and a moderately cool environment was the most favourable state for its susceptibility. In fact, the risk from the virus is reduced significantly in high temperature environment. Warm countries and places were likely to be less vulnerable. We identified various degrees of vulnerability based on temperature and specified countries for March and April. The maximum reported case, as well as death, was noted when the temperature was in the range of around $275^{\circ} \mathrm{K}\left(2^{\circ} \mathrm{C}\right)$ to $290^{\circ} \mathrm{K}\left(17^{\circ} \mathrm{C}\right)$. Countries like the USA, UK, Italy and Spain belonged to this category. The vulnerability was moderate when the temperature was less than around $275^{\circ} \mathrm{K}\left(2^{\circ} \mathrm{C}\right)$ and countries in that category were Russia, parts of Canada and few Scandinavian countries. For temperature $300^{\circ} \mathrm{K}\left(27^{\circ} \mathrm{C}\right)$ and above, a significantly lesser degree of vulnerability was noted. Countries from SAARC, South East Asia, the African continent and Australia fell in that category. In fact, when the temperature was more than $305^{\circ} \mathrm{K}\left(32^{\circ} \mathrm{C}\right)$, there was a unusually low number of reported cases and deaths, (till April, global maximum temperature reached upto $310^{\circ} \mathrm{K}\left(37^{\circ} \mathrm{C}\right)$ ). For warm countries, further analyses on the degree of vulnerability were conducted for the group of countries from SAARC and South East Asia and individual countries were compared. We also showed countries can switch from one vulnerability state to another based on the variability of temperature. We provided maps of temperature to identify countries of different vulnerability states in different months of the year.

That influence of temperature on the virus and previous results of clinical trials with similar viruses gave us a useful insight that regulating the level of temperature can provide remarkable results to arrest and stop the outbreak. Based on that knowledge, some urgent solutions are proposed, which are practically without side effects and very cost-effective too.
\end{abstract}




\section{Introduction:}

The recent pandemic of COronaVIrus Disease 2019 (COVID-19) and its rapid spread worldwide [1,2] brought the whole human civilization to a standstill. The responsible virus for the disease is Severe Acute Respiratory Syndrome CoronaVirus 2 ( $\boldsymbol{S A R S} \boldsymbol{S} \boldsymbol{C o V}$-2) [3]. Detailed analysis of the characteristics of the virus and the nature of the disease is outlined in current research $[4,5]$.

The disease first originated in the Wuhan Province of China. The case of hospital admission was first reported on $12^{\text {th }}$ December 2019 and since then till $15^{\text {th }}$ March there were 80,995 reported cases in China with 3,203 confirmed deaths [2]. Various analyses on the COVID-19 spread in China were detailed in a recent study[6]. That figure all over the globe reached $\mathbf{1 , 0 0 0 , 2 4 9}$ and $\mathbf{5 1 , 5 1 5}$ respectively [2] on $3^{\text {rd }}$ April 2020, since 31 December 2019. Those are $\mathbf{1 9 , 8 4 5 , 7 8 8}$ and $\mathbf{7 3 1 , 2 6 3}$ respectively [2] on $10^{\text {th }}$ August 2020. Geographic distribution of COVID-19 cases worldwide in early months of pandemic is presented in Fig.1 and cases are mainly seen prevalent in the northern hemisphere. Later months, countries of Southern Hemisphere were similarly affected. Because of the highly contagious in nature [3,7], most of the countries worldwide started lockdown situation from around third week of March [8].

Several facts highlighted that the spread of recent Coronavirus pandemic showed some geographical preferences (Fig.1). During early days of pandemic, countries and cities with moderately cold winter temperature indicated a rapid spread (UK, Italy, Spain, France, northern USA etc.) compared to warm countries (e.g., countries from the African continent, Indian subcontinent and, Australia) [1,2]. Moreover, very cold countries like Canada, Russia and Scandinavian countries only showed moderate severity. Interestingly, some countries that suggested moderate severity started showing a sign of more severity from the end of April. More importantly, it happened in spite of a global lockdown situation. Over the same time, some warm countries (e.g, Brazil, Chilli) also suggested an increase in severity [1,2].

On a regional basis, compared to warmer places, colder regions were seen more affected. During February and January 2020, a sub-zero minimum temperature was noted in the Wuhan province of China where the outbreak was reported first. Wuhan experienced maximum severity in terms of the death toll and the rapid rise of infected patients. In February this year, the following cities (Rome in Italy, Tehran in Iran, Seoul in South Korea) all experienced a sub-zero minimum temperature and coincidentally showed a sharp increase in the number of infected patients. Those cities were the epicentres of the outbreak of respective countries. The numbers of infected people in Italy, Iran, South Korea are reported to be 115242, 50468 and 10062 (as of $3^{\text {rd }}$ April 2020 since 31 December 2019) [2].

Close connections between epidemics and seasons are previously identified for mid-latitude temperate regions; which is November till March in the Northern Hemisphere, while May upto September in the Southern Hemisphere $[9,10,11]$. In temperate regions, absolute humidity minimizes in winter alongside temperature which becomes more susceptible to certain virus transmission and survival [10].

Some results of clinical trials are discussed. A laboratory study using a seasonally dependent endemic virus that has close resemblance with Coronavirus also confirmed the dependence of temperature and humidity on the spread of disease [11]. It showed that at a temperature of $5{ }^{\circ} \mathrm{C}$ and relative humidity $(\mathrm{RH}) 35 \%$ to $50 \%$ the infection rate was very high (75-100\%). Whereas, when the $\mathrm{RH}$ was still kept at $35 \%$, but only temperature was increased to $30^{\circ} \mathrm{C}$ the infection rate surprisingly reduced to zero [11]. As the infection rate was reduced to zero at temperature $30{ }^{\circ} \mathrm{C}$ and humidity $35 \%$ that estimation may be useful for arresting spread of similar viruses and needs further exploration.

Another virus named the Middle East Respiratory Syndrome Coronavirus (MERS-CoV) that share genetic similarity with COVID-19 was shown to remain active for a long time in low humidity and low temperature [12]. Studies with a different Coronavirus SARS-CoV (Severe Acute Respiratory Syndrome Coronavirus) also 
noted the same connection $[13,14,15]$. MERS-CoV and SARS-CoV both belong to the Coronavirus genus in the Coronaviridae family [16].

Research also studied strength and activity for a similar generic Coronavirus (viz. SARS-CoV) using a variable level of temperature and humidity [14]. It found that inactivation of the virus was faster at all humidity level if the temperature was simply raised to $20^{\circ} \mathrm{C}$ from $4^{\circ} \mathrm{C}$. Also, the inactivation was more rapid if the temperature was further increased to $40^{\circ} \mathrm{C}$ from $20^{\circ} \mathrm{C}$, suggesting the virus is extremely sensitive to high temperature. SARS could, however, be active for at least five days in typical airconditioned environments which has relative humidity $40-50 \%$ and room temperature $22-25^{\circ} \mathrm{C}$ [13]. Studies with various Coronavirus generic categories other than MERS and SARS also confirmed that low temperature significantly contributes to the survival and transmission of the virus $[14,17]$.

COVID-19 is an extremely contagious disease [3,7] as it invaded almost all parts of the globe in less than two months $[1,2]$. The nature of its transmission under variable temperature condition also needs attention. A lab experiment was conducted using guinea pigs to examine the contamination of a similar seasonal air-borne virus [11]. It studied the effect of temperature on airborne transmission as well as contact transmission. Increasing the temperature prevented airborne transmission but could not stop contact transmission. When guinea pigs were kept in separate cages for 1 week at a temperature of $30^{\circ} \mathrm{C}$, no infection took place among recipient guinea pigs. But to simulate contact transmission, if those were kept in the same cage, between $75 \%$ and $100 \%$ became infected. They, however, found no role of humidity in these experiments.

Though the knowledge of temperature sensitivity to the similar seasonal virus is recognised, whether any early warning systems can be proposed on various space and time scales is yet to be determined [18]. The role of weather on similar air borne viral diseases and the recent spread of COVID-19 was also studied in various analyses. Research confirmed dependencies on temperature and humidity $[14,15,19]$; wind speed and surface pressure [19] for the spread of virus. A systematic review to understand the effect of temperature on COVID-19 was also conducted [21] . It collected numerous recent journal submissions (around 16 in number) and almost all of them indicated a strong dependence on temperature. The role of global temperature on the transmission of COVID-19 worldwide was mentioned first by the author in a recent work [22]. That knowledge was further elaborated in a subsequent study by presenting a global temperature spatial map and comparing with vulnerability worldwide [23]. There are potential that the knowledge of such analyses can be used for the benefit of human society in the current emergency situation. The present analysis is an extension work to investigate those effects further. It also identifies countries those are more advantageous/ disadvantageous stage than others in various months and seasons. That knowledge has implication for future planning and setting mitigation strategy.

It is an extremely contagious disease [3,7] and has very high epidemic potential. Scientists from different fields are working tirelessly to mitigate the crisis. Popular known methods to treat disease are plasma therapy, vaccine development, medication etc. But those are not yet comprehensively tested; in addition, time consuming and with potential side effects. Lockdown and social distancing can be a temporary solution, as the economy and mental health also need attention. With those emergency situations in mind, some effective, easy solutions were also proposed on $17^{\text {th }}$ March 2020 [22] and further elaborated here. These are without side effects, no funding is required, no vested interest involved and can be practised in own home. These additional measures, apart from existing guidelines [3,7], can greatly benefit to overcome the crisis.

This article is based on the idea whether the variable global temperature has any role in the transmission of virus globally and how that knowledge can be used to arrest the rapidly spreading disease.

\section{Methodology and Data:}


This study analysed Global Air Temperature data from NCEP/NCAR Reanalysis product [24], a joint product from the National Center for Atmospheric Research (NCAR) and National Centers for Environmental Prediction (NCEP). The data is freely available [25]. It has a temporal coverage of Monthly as well as Daily values from 1948 January till recent dates. The long-term monthly mean of this data is available and derived for years 1981 - 2010. The spatial coverages extend all over the globe and has 17 vertical levels. In this analysis, I only considered the lowest level near the surface which is $1000 \mathrm{mb}$. For air temperature, I presented the climatology (30 years average), as well as some daily composites using compositing technique. Results were also compared with another reanalyses product ERA5 [24a] and observations are similar and hence not shown here. To find differences between two sets of data, the Method of Mean Differences was applied. The level of statistical significance was derived using the student's t-test. Data related to COVID-19 are collected from freely available site [26].

\section{Results:}

\subsection{Analyses based on Temperature and spread of the Virus}

As temperature play a very key role in spreading Coronavirus $[12,13,14,15,17]$ and also especially COVID-19 $[19,20,21]$ we analysed it further by using a spatial plot of global monthly mean air temperature (Fig 2). Later it was compared with the vulnerability to the disease worldwide.

\subsubsection{Mean Spatial Temperature Globally}

Mean global temperature spatial plot for March 2020 is shown in Fig 2a, when lockdown started [8] and the disease affected most of the countries globally. Though the lockdown started mainly from around third week of March in most countries, the effect of lockdown on the spread of the disease was expected to be noticed around April. Fig.2b is a spatial plot for the month of April 2020. Whereas, Fig. 2c covers the period when the disease made its presence globally $\left(15^{\text {th }}\right.$ Feb) till the last day of April 2020.

Temperature threshold: Cold temperature

Different vulnerability situation was observed for moderate cold countries and extreme cold countries.

Moderate cold: The first ten countries (and number of death counts till $3^{\text {rd }}$ April) in descending order are mentioned: Italy $(13,917)$, Spain (10003), United States (6,053), France (4,503), China $(3,326)$, Iran $(3,160)$, United Kingdom (2,921), Netherlands (1,339), Belgium (1011) and Germany (872) [2]. These countries showing maximum vulnerability, belonged to the moderate cold category. Mean temperature varied between the range of around $275^{\circ} \mathrm{K}\left(2^{\circ} \mathrm{C}\right)$ to $290^{\circ} \mathrm{K}\left(17^{\circ} \mathrm{C}\right)$.

Severe cold: Though Laboratory experiments to my knowledge did not conduct any study relating to lower temperature threshold, but Fig. 1 and 2a suggested, lower temperature threshold may also be important. Here are some statistics [2] for reported Cases (and Deaths) for countries below $275^{\circ} \mathrm{K}\left(2^{\circ} \mathrm{C}\right)$, viz., Iceland 1319(4), Finland 1518(19) and Canada 11268 (138); all those showed comparatively low death counts till $3^{\text {rd }}$ April.

\section{Temperature threshold: High temperature}

Interestingly, countries having temperature more than $300^{\circ} \mathrm{K}\left(27^{\circ} \mathrm{C}\right)$ showed unusually low death rate compared to the overall statistics. Countries from the South Asian Association for Regional Cooperation (SAARC), South East Asian Countries (SEAC), the African continent and Australia all lied in that zone 
and all had low death counts (Fig. 1, Fig. 2a). African countries lying in that temperature zone reported insignificant infected cases as well as deaths. That temperature zone excluded countries with higher reported case among African continent (countries of northern boundaries e.g., Algeria, Egypt and Morocco and Southern boundaries e.g., South Africa). For Australia, that statistics of the reported Cases (and Deaths) were 5224 (23); in fact, no death was reported till $3^{\text {rd }}$ of April [1] in regions when the temperature is higher than $300^{\circ} \mathrm{K}\left(27^{\circ} \mathrm{C}\right)$. Almost all reported cases and deaths for Australia were around South East part of the country where the temperature was below $300^{\circ} \mathrm{K}\left(27^{\circ} \mathrm{C}\right)$ (Fig. 1 and Fig. 2a). Few other countries falling in that temperature threshold with reported Cases (and Deaths) were Malaysia 3116 (50), Singapore 1049(5) and Thailand 1875 (15) [1].

Certain clinical tests found the infection rate for some seasonal air borne virus was reduced to zero at temperature $30{ }^{\circ} \mathrm{C}$ at certain humidity level [11]. Here I show that the vulnerability to COVID-19 is reduced drastically even at $27^{\circ} \mathrm{C}$, without considering any effect of humidity. In addition to that, when the temperature was above $305^{\circ} \mathrm{K}\left(32^{\circ} \mathrm{C}\right)$, an unusually low number of the reported cases, as well as deaths, was observed ${ }^{1}$.

These analyses indicated some rough temperature threshold for the spread and vulnerability to COVID-19 as follows: i) $275^{\circ} \mathrm{K}\left(2^{\circ} \mathrm{C}\right)$ to $290^{\circ} \mathrm{K}\left(17^{\circ} \mathrm{C}\right)$ - maximum reported Cases as well as Deaths; ii) $<275^{\circ} \mathrm{K}\left(2^{\circ} \mathrm{C}\right)$ death reporting was low; iii) $300^{\circ} \mathrm{K}\left(27^{\circ} \mathrm{C}\right)$ and above- significantly less number of reported deaths compared to overall global death counts; iii) $>305^{\circ} \mathrm{K}\left(32^{\circ} \mathrm{C}\right)$ - an unusually low number of reported Cases as well as Deaths.

Fig. 2b is the spatial plot of global temperature for April 2020 which is tested again and the main conclusion relating to temperature threshold and vulnerability remain the same; and it is also true for Fig.2c.

The vulnerability to the disease worldwide was analysed further based on certain data on the day of $1^{\text {st }}$ May [26]. To examine that data till the $1^{\text {st }}$ of May (Table 1) we compared global temperature map from $15^{\text {th }}$ Feb till the end of April (Fig. 2c). We find results are consistent.

\subsubsection{Examining Reported Cases and Deaths}

Based on location, testing facility and other various reasons reported cases are likely to vary. As death reporting is usually authentic, we considered 'Deaths' as a better metric. Moreover, the absolute number of deaths vary based on population. Hence to analyze the degree of vulnerability, 'Deaths/Million' population of a country is chosen as the best indicator in this analysis.

In Table 1, I have presented a few statistics showing situation update/ performances of various chosen countries [26]. Some countries, especially those are developing could have poor reporting strategy and inadequate facilities. Tests /Million population are expected to be comparatively low for those countries, as also reflected in Table 1 (last column). We should note that data or statistics presented in Table 1 could vary slightly and may not be accurate. However, those limitations do not affect the main results of these analyses.

Tests /Million populations were maximum for Iceland, which was reflected in the highest number of infected cases per million (column 4). Death/Infected (column 5) is a parameter that could indicate the performance of medical treatment country-wise and expected to be lower for developed countries. However, it is also linked with the number of more overaged population and number of testing etc. Death/Infected (\%) was highest in European countries in spite of advanced health care system, that may indicate a high ageing population. The same was the lowest for Singapore (.1\%), which had high testing rates amongst all warm countries.

Data of all countries from South Asian Association for Regional Cooperation (SAARC) were presented which are Afghanistan, Bangladesh, Bhutan, India, Maldives, Nepal, Pakistan and Sri Lanka. All countries of South East Asian region were also presented in Table 1. Those are Singapore, Cambodia, Malaysia, Vietnam, Thailand, Indonesia, Philippines and Myanmar. Among those, some are very popular tourist spots and some are popular international business hubs where more transmission of the disease by foreign travellers are 
expected. In spite of the varied level of testing, infrastructural facility, population density, varying degree of lockdown restriction and many dissimilarities among each country there was still one common factor. All those countries had very less death per million population. For SAARC countries it was 2 and under; whereas, for South East Asian countries (SEAC) it was 6 and under. Among these countries, Singapore did maximum testing per million, which was even comparable with developed countries. That large count was reflected in the higher count for infected per million compared to other countries in that group, though not in the death count. Among those two groups of countries, the number of deaths in one day $(01 / 05 / 2020)$ was higher in India and Pakistan compared to the rest (column 6), which was a common reflection of their high population.

Following Table 1, we found the least vulnerable countries had a very less count of Deaths per Million, which was under 1 (column 3). That count for less vulnerable countries were 10 and under. Result of few Moderate cold countries and very cold countries were also presented. For moderate cold countries, the Deaths per million were very high which even exceeded 400 in some countries. Though the USA ranked first in terms of total number of deaths and reported cases [1] but being $3^{\text {rd }}$ largest populated countries in the world [27], the ranking of the USA in Table, 1, column 3 was lower than European countries. For very cold countries that count was less than 100 for most cases.

Following temperature thresholds upto April, we categorised countries based on vulnerability as follows:

Category I: Moderate Cold - between $275^{\circ} \mathrm{K}\left(2^{\circ} \mathrm{C}\right)$ to $290^{\circ} \mathrm{K}\left(17^{\circ} \mathrm{C}\right)$ - Most Vulnerable. Countries like USA, UK, Spain, Italy, France etc.

Category II: Very Cold - less than $275^{\circ} \mathrm{K}\left(2^{\circ} \mathrm{C}\right)$ - Moderate Vulnerable; e.g. Iceland, Finland, Canada, Russia etc.

Category III: Moderate warm - greater than $300^{\circ} \mathrm{K}\left(27^{\circ} \mathrm{C}\right)$ - Less Vulnerable; e.g., SAARC, South East Asian countries, African continents, Australia.

Category IV : Very warm - greater than $305^{\circ} \mathrm{K}\left(32^{\circ} \mathrm{C}\right)$ - Least Vulnerable. Part of African continents and Australia

There could still be a very few countries suggesting as outliers. Those could be related to relaxed/ effective social isolation policy and preventive measures, low/high testing facility, relaxed/ regulated overseas arrivals, poor/advanced infrastructure, inadequate/ appropriate medical intervention on time, other favourable/ unfavourable atmospheric conditions etc.

\subsubsection{Statistical Analyses}

Fig.3 showed vulnerability to COVID-19 measured in terms of Deaths per Million, upto ${ }^{\text {st }}$ of May, 2020. Fig.3a suggested all Warm countries together (SAARC and South East Asian countries (SEAC), continents of Australia and Africa) had significantly low death rates compared to cold countries. Mean and standard deviation of moderately cold $(395.8,125.0)$, very cold $(41.5,34.8)$ and warm countries $(2.1,2.4)$ suggested a clear distinction. In the group of warm countries, there were enough dissimilaities among each other in various respect (varied testing level, popular tourist destination, infrastructural facility, other atmospheric conditions, developed/developing status of countries etc.). The low mean and standard deviation clearly indicated how strong was the role played by temperature. The method of mean difference is applied among the three categories and to test the level of statistical significance, 't' test is used. The difference between 
each other in the three categories are significant even at the $99 \%$ level. In Fig. 3b, we further elaborated on warm countries and presented box plots focusing on countries from SAARC and SEAC. Each group comprises of a total of 8 countries. The SAARC group of countries indicated the lower mean value (1.0) and standard deviation (0.8) than the group of SEAC (2.6 and 2.2, respectively). Fig. 3c further focused each individual countries from Fig. 3b. Among SAARC countries, Pakistan, Afganisthan and Maldives showed highest rate; while from SEAC, countries with high death counts were Combodia and Philipines. Fig.S1 is same as Fig. 3 though considered reported Cases per Million instead of Deaths. Countries with more number of testing sometimes report more cases (e.g., Singapore, Maldives and Iceland). That is one of the reasons for large standard deviations in Fig S1a. Like Death, there is a very clear distinction between three categories (Fig S1a). In Fig.S1b, we excluded two outlier countries Singapore and Maldevis those did very high testing compared to the rest. The boxplot of SAARC and SEAC do not differ much. In Fig.S1c too, we excluded those two outliers for general comparison. As the reported case is heavily dependent on number of testings and other factors, rankings of individual countries in Fig.S1c differ to that from Fig.3. Among SAARC countries, the ranking of Pakistan was highest for both, the Deaths as well as reported Cases per million.

Even till today (10 ${ }^{\text {th }}$ of August 2020), Deaths per Million for all countries from SAARC and SEAC are below 34 [26]. On the otherhand, Death per Million for USA, UK, Spain, Italy, France, Sweden, Belgium over the same time are all above 465 [26] . However, because of large population, India is now one of the highest ranked in overall counts of total Deaths, as well as Cases.

\subsection{Effect of Temperature Regionally and Transition Phase:}

Regional temperatures within a country can vary to a large degree, (even $\sim 25^{\circ} \mathrm{C}$ for the USA, Fig. 2 ). Hence vulnerability of any country will also depend on regional variations of temperature and discussed further.

\subsubsection{Regional Variation.}

Fig. 4a, indicated that the southern part of Canada was mostly affected compared to the rest of the country. Interestingly, that region only lied in the most vulnerable temperature zone (Fig. 2c). A transition was noticed from March to April and more parts of southern Canada entered in moderately cold category in May indicting a rise in vulnerability. The spatial plot of Canada (Fig. 4a) and temporal pattern (Fig. 4b) indicated such features. The daily death count increased during the beginning of April (Fig. 4b). A very high number of daily deaths were reported on the $1^{\text {st }}$ of May (Table $1,6^{\text {th }}$ column), which was comparable to most vulnerable countries.

In spite of a lockdown situation globally [8] if there was an increase in Deaths/Cases to some countries that needed attention too. At the end of April, many countries started moving from one vulnerability state to others, e.g., Russia, Canada and some Scandinavian countries. For Russia, new cases reported on $7^{\text {th }}$ May was 10,559, which was $2^{\text {nd }}$ highest reported case after the USA[26]. Canada also reported very high death on that day, which was 189, and again comparable with vulnerable countries [26]. For Sweden, the death reported on $7^{\text {th }}$ May was 87 which was relatively high compared to the overall population of $\mathbf{1 0 , 0 8 9 , 7 9 5}$ [26]. These countries were very cold in March, though phased out to moderate cold phase at the end of April.

\subsubsection{The Transition of Spatial Pattern}

A recent research [19] studied the effect of temperature on the spread of COVID-19 in Italy. It showed only $2^{\circ} \mathrm{C}$ rise in temperature can have a comparable effect on the transmission of the virus. The effect of small change in temperature even for $2^{\circ} \mathrm{C}$ to $2.5^{\circ} \mathrm{C}$ was analysed and discussed for a few continents in Fig 5 (Europe), Fig. S2 (Africa) and Fig. S3 (South America).

A spatial plot particularly focused on Europe (Fig. 5) suggested that UK was still in the most vulnerable zone in April; whereas, southern Europe turned warmer (Fig. 5 a and b). Scandinavian countries like Sweden started entering into most vulnerability zone from moderate vulnerability state (Fig. 5 a and b). As Europe 
turned warmer from moderately cold, death rate decreased and the same pattern is observed till the beginning of August.

For Africa, the region of least vulnerability was marked by dark red (Fig. S2). The temperature increased around latitude $10^{\circ} \mathrm{N}-15^{\circ} \mathrm{N}$ in April and Table 1 (6th column) showed no new death was reported to those countries. Questions could be raised about poor testing and reporting in those African countries. One reason could be as death was reported zero, those underdeveloped countries may not have considered testing a priority. Moreover, in Australian continents without much of an issue of testing and reporting also suggested similarly. In fact, part of western Australia and northern territory (least vulnerable region, Fig.2) did not have deaths and practically few reported cases [1] (hence not shown in Table 1). A shift in high temperature region in Africa from south to north during March to April gave an indication of how the vulnerability can shift regionally and gave rough time estimations of that transition. Northern territory of the continent turned warmer in April from March, while southern territory (that include south Africa) started to become cooler (Fig S2).

As $2^{\circ} \mathrm{C}$ change of temperature can influence the transmission of the disease [19], I wanted to explore that for South America (Fig. S3) too. Some countries from South America suddenly started an increase in deaths and reported cases. On $7^{\text {th }}$ May, Brazil reported new daily death 667 , the $2^{\text {nd }}$ highest after USA [26]. The lowering of temperature in Southern Brazil $\left(297^{\circ} \mathrm{C}\right.$ to $291^{\circ} \mathrm{C}$ in April) is clearly distinct in Fig. S3b to that from Fig. S3a.

\subsubsection{Temporal Pattern.}

Fig. 6 showed daily confirmed COVID-19 Deaths per Million in a form of rolling 7 -day average upto $6^{\text {th }}$ May. Those statistics were consistent with the number of total Death counts per Million (Table 1 , $3^{\text {rd }}$ column). There were clear distinctions throughout the time period among moderately cold, very cold and warm countries. All warm continents e.g., Asia, Africa and Australia, those belonged to the less vulnerable category, suggested a very nominal daily death count rate compared to the rest (not visible as merges with $\mathrm{X}$ axis). The bottom three curves are for Russia, Brazil and Canada respectively. All three were showing a rising trend and we discussed earlier those three were in the transition state. Russia and Canada were turning from very cold to moderate cold; whereas, Brazil from warm to cold and all cases Death rate was increasing. For the USA, UK, Italy and Spain all suggested very high count throughout and all already achieved a peak and were shown in the declining state.

In terms of population, three highly populated countries are considered here viz., the USA, Brazil and India (world ranking $3^{\text {rd }}, 6^{\text {th }}$ and 2 nd respectively) [27]. In terms of population, three highly populated countries are considered here viz., the USA, Brazil and India (world ranking $3^{\text {rd }}, 6^{\text {th }}$ and 2nd respectively) [27]. A plot of daily death upto $2^{\text {nd }}$ May was presented for those three countries (Fig. 7a). The USA, a vulnerable country showed a very high daily count, Brazil in a transition phase from warm to cooler state, suggested high death count with a comparatively steeper rise in later periods. India the less vulnerable country was moving from warm to warmer. It reported much less death count compared to the rest two.

Temporal pattern of these three countries is also consulted upto recent period in Fig $7 \mathrm{~b}$. They ranked $1^{\text {st }}$, $2^{\text {nd }}$ and $3^{\text {rd }}$ respectively globally in terms of total Cases and daily Deaths on $11^{\text {th }}$ August 2020 [26]. The USA peaked around April and after a decline it again started showing a rise in recent period. Brazil reached a peak at around June and still continued with that trend without a decline. Whereas, India is showing a steady rise and did not reach a peak yet. The 7-day average shows the maximum count for India is the lowest till date; USA the highest, followed by Brazil. The steady rising trend of India and its consequence indeed deserve attention.

Based on the discussion, it is possible to determine whether the risk from the virus of a specific country as a whole and region-wise is increased or decreased during different time periods.

\subsection{Future Predictive Maps based on Temperature:}


Climatology of temperature is prepared globally for different months (Fig. 8, Fig. S4-S8). Following the current analyses, it would indicate predictive maps of vulnerability for different months based only on temperature. Figure $8(\mathrm{a}, \mathrm{b})$ are for July and August respectively, while Fig. S4-S8 for rest other months. Those show Fig 2a is consistent with Fig S5 (top) and Fig. 2b with Fig S5 (bottom), which are for the month of March and April respectively. As we verified it for last March and April (2020) with the climatology of those two months, we may expect the predictive maps would be very similar for other months too.

Future predictive maps can indicate, which countries are in advantageous/ disadvantageous state in the coming months based only on temperature variation. It indicated that during July, South America, Australia and South Africa will turn colder (compare between Fig. 2 and Fig. 8a) and need additional risk-based preparedness. Iceland, Russia will turn moderate cold from very cold. Europe will turn warmer and will reduce risks. Following this future predictive map, the death rate in Europe indeed reduced this July; while South America, Australia, South Africa showed a rise. Iceland and Russia also reported increase in cases as well as deaths.

Such future predictive maps can give ideas of associated risks to different countries month-wise and the direction of transitions. It will be important for every country for future preparedness and planning.

\subsection{Additional Points need Attention}

Few additional points need attention for preparing future strategy.

i) More use of Air Conditioning (AC) in very warm countries: In June, July some countries reached more than $310^{\circ} \mathrm{K}\left(37^{\circ} \mathrm{C}\right)$ temperature (Fig. 8a; Fig. S6,bottom). In that uncomfortable range of temperature, rich to middle-income group of people and economically affluent countries are likely to use more AC. That might cause more spread of the disease within the same household, especially in highly populated countries. Similar category Coronavirus was found active for at least five days in typical airconditioned environments [13]. That could be one possible reason for recent surge in Cases and Deaths in very warm $\left(>310^{\circ} \mathrm{K}\right)$ countries e.g., countries like Iran, Iraq etc. in July-August.

Air circulation for half an hour daily and regular disinfecting AC premise could be useful to arrest spreads.

ii) Mass Gathering: Mass gathering in any city or places later showed a surge in infections and deaths after certain days of lag. Scafetta also discussed that issue for various places, including Carnival in Louisiana state, USA [19]. Recently, Black Lives Matter protests took place in many parts of the USA. Many did not follow precautionary measures and distancing rule, which may have certain bearings in the surge in Cases and Deaths in the USA since beginning of July (Fig. 7b). Any mass gathering needs further attention/ analyses to prevent future outbreaks.

iii) Outliers Countries and states: There could be very few countries standing as outliers. Examples of outlier countries from South America are Uruguay and Paraguay. They reported unusually low deaths compared to neighbouring countries [26].

An example of outlier state is Kerala from India. The first case of COVID-19 in India was spotted in Kerala. In spite of high population density, they could manage the number of deaths remarkably low compared to all the neighbouring states. That trend is maintained throughout the period till date. All neighbouring states have very similar weather conditions. Kerala set an example to the country as well as at international level. On the contrary, only one state Maharashtra in India is accounting for roughly $40 \%$ of the total deaths of the country [33a].

Those suggest country level and state level effective intervention can play a vital role. Outlier countries and cities need more attention in gaining insight for future global action.

iv) Case example of a Country (South Africa from African Continents) and State (Victoria in Australia): Among land-locked countries from African Continents, South Africa reported maximum Deaths as well as Cases. South Africa (at the southern part of the continent) is comparatively cooler than most African countries. In June and July, it was coldest among all the African countries (see Fig. S6 and 
Fig. 8a, even reached less than $290{ }^{\circ} \mathrm{K}$ ) and simultaneously increased daily death counts. Interestingly, South Africa has the highest total testing than other countries of the continent. Deaths per Million in South Africa is highest among all countries from the continents and it is 181 till $11^{\text {th }}$ August 2020 [26]. The same count for most of the countries of African continent is below 20 .

Similarly, the state Victoria in Australia noted a Surge in Cases as well as Deaths in recent period. After a peak at around April 2020, Australia reported practically zero daily death during whole of June. It suddenly showed a $2^{\text {nd }}$ surge and daily Death count (absolute count, 3-day rolling average, as well as 7-day rolling average) reached highest on the day of reporting (11 ${ }^{\text {th }}$ August) [26]. Situated in the south-east part of Australia, Victoria was the coldest part of the country in July (temperature even less than $285^{\circ} \mathrm{K}$, Fig $8 \mathrm{a}$ ) and interestingly showed maximum surge in cases and deaths in recent days compared to other states.

Such observation strengthened the fact that the role of temperature cannot be over-ruled on the spread and vulnerability of the disease, regionally as well as globally.

v) Major Cities: This is an extremely contagious disease and single contamination through a foreign carrier/traveller can multiply exponentially among locals. Megapolises like New York, Mumbai, London were expected to be infected more than its suburb and it was, in fact, the case. All these factors need to be taken into account in doing any statistical analyses. This analysis is free from such biases.

vi) Risk less in Summer than winter? Risk of a person from the disease also depend on how much virus entered in the body. In summer, if anyone is in the cold Air-Conditioned (AC) room the whole day with a COVID-19 infected person, it could be riskier than anyone in winter who are outside in open air with a COVID-19 patient for a short time. It explains why many young doctors and nurses without morbidity conditions died. Many police and security service personal also died though they were sound in health. Again, if people are outside in summer with a COVID-19 infected person, the risk is less compared to winter. Studies suggested that air borne seasonal viral transmission is reduced in high temperature environment [11] .

All these analyses are useful to set proper mitigation strategy to tackle the crisis.

\subsection{Possible Solutions:}

The above analyses highlighted that temperature plays an important role in transmissions of Coronavirus $[12,13,14,15,17]$ that include COVID-19 [19,20,21]. Warm temperature drastically reduces its impact. Hence following urgent measures (also mentioned earlier $[22,23,23 \mathrm{a}, 23 \mathrm{~b}]$ ) are proposed to arrest and stop the outbreak:

- Sauna facility: Usually hotels, gyms, leisure centres have existing Sauna facilities. Also, mobile and Caravan Sauna facilities can be thought of in future.

- Portable Room Heater: Stay close to a portable room heater twice a day around half an hour. Being portable in nature, it can be moved around and many people can avail that facility in a flexible way. Room heaters can also be useful for disinfecting purposes. purposes.

- Portable Room Heater: Stay close to a portable room heater twice a day around half an hour. Being portable in nature, it can be moved around and many people can avail that facility in a flexible way. Room heaters can also be useful for disinfecting purposes. purposes.

- Regulate room temperature of Air Conditioning (AC): Maintain room temperature of AC a bit higher than usual. Maintaining comfort level, a high temperature threshold can be regulated inside offices, schools, colleges, shopping malls etc. Attention should be more on sensitive places like old care homes, health centres, and hospitals (other than special treatment units where cold temperature is essential or recommended).

- Disinfect any place using High Temperature: Before start of office, school or business, temperature of premises may be kept very high, (say, $60^{\circ} \mathrm{C}$ ) for half an hour. For airports, train and bus, same method of disinfecting could be thought of. Optimum temperature and duration can be tested easily. For any external object or material, disinfecting using very high temperature could be a useful solution. 
- Blow dryers (Hair dryer) : Inhale hot air through nose few times a day to kill virus in nasal cavity.

- Hot Drinks: Hot drinks (could be tea, coffee, warm milk, hot water with lemon, etc.), gargle with warm salt water few times a day to destroy virus in throat.

The last two measures are proposed because the virus, which is very sensitive to Temperature, mainly enters through the nose (WHO) [3]. Testing is done with swab from nasal cavity and back of the mouth. High temperature will reduce the number in nose and throat where the virus largely accumulates. Thus, body will have strength and time to defend the disease easily. These measures described above could be very effective when people are in the asymptomatic, pre-symptomatic state or initial stage of disease. An overview depicting actions towards Solutions in a form of schematic is presented in Fig.9.

The main point in this analysis is that the virus is very sensitive to temperature. Based on that knowledge these few measures are proposed. All solutions, as supported by science, can further be strengthened by clinical trials, side by side. Many simple, easy procedures serving the purpose can be thought of; some could be applicable to warm countries and some to cold countries. Few options for people of lower income groups and for rural and remote locations are mentioned.

- Green House (glass): It would be useful in poor countries and rural places without electricity. During the day, bright sunshine can provide heat by Green House effect.

- Outside Raw Fire: In underdeveloped countries and rural places, people usually circle round in a camp-fire style fire in winter. They use dry leaves and spare woods for a small fire. That heat in winter could be useful.

- Substitute of Blow Dryer (Hair Dryer) and Room Heater: While cooking, all members of the household could be, in turn, stay close to the heat source, for, say, half an hour a day. Also, each individual can use separate folded cotton cloths to take heat from the cooking container and use on the nose.

Study showed SARS-CoV-2 is more infectious than some other Coronaviruses [34]. The usual incubation period for COVID-19 is around 14 days [7]. The virus can stay in the human body for a few days without showing symptoms though still could be a carrier [3,7]. As it is difficult to trace mild or pre-symptomatic infection, it has greater epidemic potential [34]. Given the emergency situation, lots treatment/ medicines are desperately tried which are fraught with risks of serious side effects. On the contrary, this solution has practically zero side effects. This study suggests the majority of world populations need to be well prepared before the coming winter. This is an extremely contagious disease [3,7]. Social isolation and lockdown can be a temporary solution, as the economy and mental health also need attention.

These measures, as mentioned, are likely to reduce the spread dramatically. If few of these measures are implemented worldwide, it will have a major impact to arrest the spread of the virus.

\section{Caution and Additional Points}

Caution: If people already developed major symptoms, then all these methods discussed will not be effective and proper medical advice need to be solicited.

\section{Additional Points:}

- Water shortage: Whether frequent Hand Washing can be replaced by heat sensor-based hand dryer (normally found in a washroom).

- Plastic Disposal: Personal Protective Equipment (PPE) are single use. World is already under stress due to problems of disposing Plastic. If PPE can be disinfected using heat-based solutions and reused. It can be tested in laboratory and could prove very beneficial.

- Face Shield/Visor: In busy public places, mass gathering, and cold premise, face shield will give additional protection. The virus can also enter through eyes (ECDC).

- Contact Transmission: For warm, highly populated countries, contact transmission could play important role and appropriate measures can be taken. E.g., Air Conditioned (AC) premises, where mass gathering happens need disinfecting on a regular basis. 
- Air Circulation: In all AC room, fresh air circulation for half an hour a day is advisable. For warm countries, that timing around noon to early afternoon, when daily temperature is highest, could be more beneficial.

\section{Conclusions:}

This article investigated the influence of temperature globally in the spread and vulnerability to COVID-19. It showed the temperature was a crucial factor in transmitting the virus. The most favourable state for the spread of the virus was moderately cool places and countries; whereas warm countries were likely to be less affected. Temperature dependencies were also noticed in clinical trials those involved similar category Coronavirus (MARS, SARS etc.) and seasonal influenza/flu virus.

For analysing vulnerability, Deaths per Million population was considered as a useful and effective metric. Four different categories of vulnerability were identified based on temperature variations - which are moderately cold, very cold, moderately warm and very warm. Focusing on Temperature Range (upto April), the max reported Cases, as well as Deaths, were noted when the temperature was moderately cold, which was between the threshold of around $275^{\circ} \mathrm{K}\left(2^{\circ} \mathrm{C}\right)$ to $290^{\circ} \mathrm{K}\left(17^{\circ} \mathrm{C}\right)$. Based on temperatures of March and April, the USA, UK, Italy, Spain, France etc. belonged to this category. The vulnerability was moderate for very cold countries, i.e., when the temperature was less than $275^{\circ} \mathrm{K}\left(2^{\circ} \mathrm{C}\right)$ and countries in that category for March and April were Russia, Canada, Iceland and Scandinavian countries. A significantly lesser degree of vulnerability was noted for warm countries with temperatures $300^{\circ} \mathrm{K}\left(27^{\circ} \mathrm{C}\right)$ and above. SAARC countries, South East Asian countries (SEAC), African continents and Australia belonged to that category in March and April. In fact, when the temperature was very warm, more than $305^{\circ} \mathrm{K}\left(32^{\circ} \mathrm{C}\right)$ [maximum temperature upto April was around $310^{\circ} \mathrm{K}$ ], there were an unusually very low number of reported cases as well as deaths. Some parts of Australia and African continents showed such behaviour in March, April.

Statistical analyses suggested the vulnerability to the disease was significantly different, between each other, for moderately cold, severe cold and warm countries. For warm countries, further analyses on the group of all SAARCs and SEAC were conducted and individual countries were also compared. The low mean and standard deviation for Deaths/ Millions of all SAARC and SEAC countries indicated again the strong role of temperature.

This analysis can also give some idea for regional variation of vulnerability of various countries and it specifically discussed that for Canada. Spatial variations within continents were discussed for Europe, South America and Africa for the month of March and April. Based on temperature variations, countries can move from one vulnerability state to the other. For e.g., parts of Russia, Canada started entering severe cold to moderate cold state at the end of April; whereas, Brazil and few warm countries from South America moved from warm to a less warm state. In spite of the lockdown situation worldwide at that time, those countries reported a sudden rise of death and infected cases at the beginning of May. Europe tuned warmer from moderately cold and death rate decreased in later periods.

The rolling 7-day average of daily confirmed COVID-19 Deaths per Million over the period (till the beginning of May) is also discussed. It was consistent with the total number of Deaths/Million. There were clear distinctions throughout the time period among moderately cold, very cold and warm countries. All warm continents e.g., Asia, Africa and Australia, those belonged to a less vulnerable category, suggested a nominal daily death count rate compared to the rest. The USA and European countries showed a decline at later periods, while Russia, Canada and Brazil showed a rise.

Three highly populous countries USA, Brazil and India were focused those ranked $1^{\text {st }}, 2^{\text {nd }}$ and $3^{\text {rd }}$ respectively globally in terms of total Cases and daily Deaths till today (on $11^{\text {th }}$ August 2020). In terms of daily Deaths, the USA peaked around April and after a decline, it again started showing a rise in the recent period. Brazil reached a peak at around June and still continued with that trend without a decline. Whereas, India is showing a steady rise and did not reach a peak yet. The steady rising trend of India and its consequence indeed deserve attention. 
This analysis presented future predictive maps month-wise based only on temperature variation. That could indicate, which countries are in advantageous/ disadvantageous stage in the coming months. It predicted that the situation will worsen in July for South America, Australia, Iceland and South Africa, while will improve for Europe and that indeed happened. Current analyses and predictive maps have major implications for future planning and preparedness. This study also discussed issues which are useful to set proper mitigation strategy to tackle the crisis.

Like other similar category viruses, this virus is also very sensitive to temperature. It gave a valuable insight that regulating temperature level can provide a useful strategy to arrest and stop the outbreak. Some urgent solutions are proposed based on that knowledge. It is very cost-effective and practically without side effects. These measures are likely to reduce the spread of the disease dramatically.

Acknowledgement. This study did not receive any funding and there is no conflict of interest (financial or non-financial). Figures $(2-8)$ and Fig. S4-S8 are generated from the NOAA/ESRL Physical Sciences Division, Boulder Colorado web site at https://psl.noaa.gov/data/composites/day/

\section{References.}

1. Website: Johns Hopkins University of Medicine: Coronavirus resource centre.

Web site: https://coronavirus.jhu.edu/map.html, accessed on 03/04/2020.

2. Website: European Centre for Disease Prevention and Control (ECDC): COVID-19: https: //www.ecdc. europa.eu/en/geographical-distribution-2019-ncov-cases, accessed 03.04.2020 and 10.08.2020.

3. Website: World Health Organisation (WHO): https://www.who.int/emergencies/ diseases/novelcoronavirus-2019/technical-guidance/naming-the-coronavirus-disease-(covid-2019)-and-the-virus-thatcauses-it, accessed on $8 / 5 / 20$

4. Chen Yu and Lanjuan Li, (2020), SARS-CoV-2: virus dynamics and host response, The Lancet, 20, 5, P515-516, MAY 01, 2020, DOI:https://doi.org/10.1016 /S1473-3099(20)30235-8

5. Gorbalenya AE, Baker SC, Baric RS et al. (2020) The species Severe acute respiratory syndromerelated coronavirus: classifying 2019-nCoV and naming it SARS-CoV-2. Natural Microbiology;5:536-544. https://doi.org/10.1038/s41564-020-0695-Z

6. Li Q, Guan X, Wu P, et al. (2020): Early Transmission Dynamics in Wuhan, China, of Novel Coronavirus-Infected Pneumonia. N Engl J Med.; 382(13):1199-1207.https: //www. nejm.org/doi/10.1056/NEJMoa2001316

7. Website: ECDC: https://www .ecdc. europa.eu/en/covid-19/questions-answers, accessed on 8/05/20

8. Website: Wikipedia: https://en.wikipedia.org/wiki/National_responses _to_the _COVID-19_pandemic accessed on 8/05/20.

9. Lipsitch, M and C. Viboud, (2009). Influenza seasonality: Lifting the fog, Proceedings of the National Academy of Sciences,106 (10), 3645-3646.

10. Shaman, J. and Kohn, M. (2009). Absolute humidity modulates influenza survival, transmission, and seasonality, Proceedings of the National Academy of Sciences, ,106 (9) 32433248,; DOI: 10.1073/pnas.0806852106.

11. Lowen, A. C., Mubareja, S., Steel, J. and Palese, P. (2007). Influenza virus transmission is dependent on relativehumidity and temperature. Pathogens 3, pp. 1470-1476. 
12. Van Doremalen N, Bushmaker T, Munster V J. (2013). Stability of Middle East respiratory syndrome coronavirus (MERS-CoV) under different environmental conditions. Euro Surveill.;18(38):pii=20590. https : //doi.org/10.2807/1560-7917.ES2013.18.38.20590.

13. Chan KH, Peiris JS, Lam SY, Poon LL, Yuen KY, Seto WH. (2011). The Effects of Temperature and Relative Humidity on the Viability of the SARS Coronavirus. Adv Virol; 2011:734690, doi: 10.1155/2011/734690.

14. Casanova, L. M., Jeon, S, Rutala W. A., Weber, D.J. and Sobsev M. D. (2010): Effects of Air Temperature and Relative Humidity on Coronavirus Survival on Surfaces, Appl Environ Microbiol. 76(9): 2712-2717. doi: 10.1128/AEM.02291-09.

15. Yuan, J., H. Yun, W. Lan, W. Wan g, S.G. Sullivan, S. Jia, A.H . Bittles, (2006). A climatologic investigation of the SARS-CoV outbreak in Beijing, China, American Journal of Infection Control, 34(4), $234-236$.

16. Gorbalenya, A.E., Baker, S.C., Baric, R.S. et al. (2020). The species Severe acute respiratory syndromerelated coronavirus: classifying 2019-nCoV and naming it SARS-CoV-2. Nat Microbiol. https://doi.org/ 10.1038/s41564-020-0695-z.

17. Seung W. K., M.A. Ramakrishnan, P.C. Raynor, Goyal S M. (2007). Effects of humidity and other factors on the generation and sampling of a coronavirus aerosol. Aerobiologia. 23. 239-248. 10.1007/s10453007-9068-9.

18. Fuhrmann C. (2010), The effects of weather and climate on the seasonality of influenza: what we know and what we need to know. Geography Compass 2010;4(7):718-730. https://doi.org/10.1111/j.17498198.2010.00343.x

19. Scafetta, N. (2020), Distribution of the SARS-CoV-2 pandemic and its monthly forecast based on seasonal climate patterns. Int. J. Environ. Res. Public Health, 17(10), 3493. https://doi.org/10.3390/ ijerph17103493

20. Demongeot et al. (2020), Temperature decreases spread parameters of the new COVID-19 Case Dynamics, Biology, 9,94.

21. Paulo M et al (2020), Effects of temperature and humidity on the spread of COVID-19: a systematic review, Plos One, under revision.

22. Roy, I. (2020), Combating recent pandemic of COVID-19 - An urgent Solution. March, $17^{\text {th }}$ 2020, DOI: 10.13140/RG.2.2.22632.83208

\section{Roy, I. (2020), Atmospheric Variables and Additional Urgent Solutions for Combating} COVID-19 dt $9^{\text {th }}$ April. https://www.preprints.org/manuscript/202003.0366/v2

23a. Roy, I. (2020) Influence of Temperature on the Global Spread of COVID-19. Preprints, dt 22nd June, (doi: 10.20944 /preprints202003.0366.v3)

23b. Roy, I. (2020) Combating COVID-19: Temperature could be a key. Authorea. July 07, 2020. (doi: $10.22541 /$ au.159415142.20637179)

24. Kalnay et al.,The NCEP/NCAR 40-year reanalysis project, Bull. Amer. Meteor. Soc., 77, 437-470, 1996.

24a. Hersbach, H, Bell, B, Berrisford, P, et al. The ERA5 global reanalysis. $Q J R$ Meteorol Soc. 2020; 146: 1999-2049. https://doi.org/10.1002/qj.3803

25. Website: Physical Sciences Laboratory (PSL). https://psl.noaa.gov/data/gridded/data.ncep. reanalysis.derived.html 
26. Website: https://www.worldometers.info/coronavirus/\#countries, accessed on 2.5.2020, 8.5.2020 and 10.8.2020.

27. Website: Worldometers https://www.worldometers.info/world-population/ population-by-country/ accessed on 7.05.2020.

28. Website: https://www.canada.ca/en/public-health/services/diseases/2019-novelcoronavirus-infection.html, accessed on $2 / 5 / 20$.

29. Website: https://en.wikipedia.org/wiki/2020_coronavirus_pandemic_in_Canada accessed on $2 / 5 / 20$

30. Website: https://en.wikipedia.org/wiki/2020_coronavirus_pandemic_in_the_United_States; accessed on $2 / 5 / 20$.

31. Website: https://en.wikipedia.org/wiki/2020_coronavirus_pandemic_in_Brazil\#April_2020; accessed on $2 / 5 / 20$.

32. Website: https://en.wikipedia.org/wiki/2020_coronavirus_pandemic_in_India\#April_2020; accessed on $2 / 5 / 20$.

30a. Website

https://www. worldometers.info/coronavirus/country/us/; accessed on 11/08/20.

31a. Website

https://www.worldometers.info/coronavirus/country/brazil/; accessed on 11/08/20.

32a. Website

https://www.worldometers.info/coronavirus/country/india/; accessed on 11/08/20.

33. Website: https://ourworldindata.org/grapher/daily-covid-deaths-per-million-7-day-average accessed on $10 / 05 / 2020$.

33a. Website https://covidindia.org/ accessed on 14/08/20.

34. Ferretti L. et al., (2020), Quantifying SARS-CoV-2 transmission suggests epidemic control with digital contact tracing, Science 10.1126/science.abb6936.

\section{List of Table}

Table 1: Reported Cases, Deaths and Tests of few Countries as of 1/5/2020

\section{List of Figures}

Fig. 1. Geographic distribution of COVID-19 reported cases worldwide, as of $16^{\text {th }}$ March 2020 [1].

Fig. 2. Monthly average air temperature (oK) spatial plot Globally for: a) March 2020; b) April and c) Feb 15 till April 2020. Plots are generated from the NOAA/ESRL Physical Sciences Division, Boulder Colorado web site at https://psl.noaa.gov/data/composites/day/

Fig.3. Vulnerability to COVID-19 measured in terms of Deaths per Million, upto $1^{\text {st }}$ of May 2020. a) Deaths in Moderately cold, Very cold and Warm countries are shown. In category 3, all Warm countries (SAARC and South East Asian countries (SEAC), continents of Australia and Africa) together are presented. Uncertainty at one standard deviation level is marked. b) Box plot with particular focus on SAARC and SEAC groups. c) Record of each individual country from b.

Fig. 4. Spatial and Temporal distribution of COVID-19 deaths in Canada till 2/5/20. a) Regional distribution of reported death [28]. b) The actual number of deaths reported in each day suggests a rising pattern [29]. 
Fig. 5. Mean Air temperature in March (Top) and April (Bottom) for Europe in NCEP/NCAR Reanalyses.

Fig. 6. Rolling 7-day average of daily confirmed COVID-19 deaths per million upto $6^{\text {th }}$ May 2020 [33]. India, Asia, Africa and Australia all are very low compared to the rest throughout and practically merges with X-axis (hence not visible). The bottom three curves are for Russia, Brazil and Canada respectively. All three are showing a rising trend. Top four high peak curves are for UK, USA, Spain and Italy. All four are currently in a declining state. Plot generated using: https://ourworldindata.org/ grapher/ daily-coviddeaths-per-million-7-day-average, accessed on 10/05/2020.

Fig. 7. Daily death counts of three very high populated countries e.g., USA, Brazil and India; a) upto $2^{\text {nd }}$ May $\left.2020, b\right)$ upto $11^{\text {th }}$ August 2020 . a) The USA showed very high range (maximum 2624), Brazil moderate (maximum 474) and India low (maximum 77). Note three different ranges of $\mathrm{Y}$ axis of three countries, USA[30], Brazil [31] and India[32]. b) Apart from Daily Deaths, 3 day moving average and 7 day moving average is also marked by different colours. Peaks and troughs, which arise in 3-day average plot mainly due to weekend (less) reporting issues is eliminated in 7-day average plot. Moreover, 7-day average plot also smoothed out sudden spikes which usually arises due to rectification of past reporting (as seen for India). The 7-day average shows the maximum count for India [32a] is the lowest till date; USA [30a] the highest, followed by Brazil [31a].

Fig. 8. Climatology of global temperature for July (a) and August (b).

Fig. 9. An overview depicting actions towards Solutions at Individual level (right) and General or Public level (left) in a form of schematic.

\section{Supplementary Section}

\section{List of Figures}

Fig. S1. Same as Fig.9 (a,b,c) respectively, but instead of 'Death', it presented 'Cases' per Million. In c) Maldives and Singapore are shown as outliers (upper bound skipped) and those two are omitted in b).

Fig. S2. Mean Air temperature in March (Top) and April (Bottom) for Africa in NCEP/NCAR Reanalyses

Fig. S3. Mean Air temperature in March (Top) and April (Bottom) for South America in NCEP/NCAR Reanalyses.

Fig. S4. Climatology of global temperature for January (top) and February (bottom).

Fig. S5. Climatology of global temperature for March (top) and April (bottom).

Fig. S6. Climatology of global temperature for May (top) and June (bottom).

Fig. S7. Climatology of global temperature for September (top) and October (bottom).

Fig. S8. Climatology of global temperature for November (top) and December (bottom).

[ See all Figures and Table in the attached pdf file] 